\title{
NGHIÊN CỨU GIÁ TRỊ CỦA 18FDG PET/CT DỰ ĐOÁN TÌNH TRẠNG ĐộT BIẾN GEN EGFR Ở BÊ̂NH NHÂN UNG THƯ PHỔI BIỂU MÔ TUYẾN
}

\author{
Bùi Tiến Công ${ }^{1,2}$, Phạm Văn Thái ${ }^{1,2}$, Phạm Cẩm Phương ${ }^{1,2}$ \\ Đồng Thị Hằng ${ }^{4}$, Phạm Văn Tuyến ${ }^{3}$, Hoàng Anh Tuấn ${ }^{3}$, Đoàn Minh Khuy
}

TÓM TẮT.

Mục tiêu nghiên cứu: Nghiên cứu giá trị của FDG PET/CT dự đoán tình trạng đột biến EGFR ở bệnh nhân ung thư phổi biểu mô tuyến. Đối tượng và phương pháp nghiên cứu: 114 bệnh nhân ung thư biểu mô tuyến của phổi giai đoạn IIIIb, IV được chụp FDG PET/CT, xét nghiêm EGFR trước điều tri từ 11/2018 đến 07/2020. Kết quả: Đố tuổi trung bình $62,3 \pm 8,4$, tỷ lệ nam $(63,2 \%)$ nữ $(36,8 \%)$, giai đoạn IIIb $(43,0 \%)$ và giai đoạn IV $(57,0 \%) .43,0 \%$ bẹnh nhân nghiên cứu không bộc lộ PD L1, 57,0\% BN nghiên cứu có kết quả xét nghiệm PD L1 dương tính mức độ yếu đến mạnh. Tỉ lệ đột biến gen EGFR và tỷ lệ không có đôt biến tương ứng $55,3 \%$ và $44,7 \%$. Giá trị SUVmax tại khối u phổi nguyên phát ở nhóm EGFR dương tính $(11,2 \pm 5,7)$ thấp hơn có ý nghĩa thống kê so với nhóm EGFR âm tính $(15,8 \pm 6,2)(p=0,04)$. Sử dụng biểu đồ ROC cho thây, diện tích dưới đường cong (AUC) của SUVmax trong chẩn đoán EGFR dương tính là $0,654 \quad(p<0,05)$. Kết hợp 4 yếu tố SUVmax, giới, tiền sử lá hút thuốc, cho kết quả chẩn đoán EGFR dương tính tốt hơn, cụ thể diện tích dưới đường cong (AUC) của 4 yếu tố là $0,706(p<0,05)$. Kết luân: Đăc điểm FDG PET/CT có mối liên quan và có giá trị dự đoán tình trạng đột biến EGFR ở bệnh nhân ung thư biểu mô tuyển của phổi

Tư khoá: Ung thư phổi, biểu mô tuyến, FDG PET/CT, EGFR

\section{SUMMARY}

STUDY VALUE OF ${ }^{18}$ FDG PET/CT IN

PREDICTING OF EGFR GENE MUTATION

STATUS IN PATENTS WITH LUNG ADENOCARCINOMA

Research objective: To study the value of FDG PET/CT in predicting EGFR mutation status in patients with lung adenocarcinoma. Subjects and research method: 114 patients with lung adenocarcinoma stage IIIb and IV had FDG PET/CT scan and EGFR mutation test before treatment from November 2018 to July 2020. Results: Mean age of the patients was $62.3 \pm 8.4$, male $(63.2 \%)$ female $(36.8 \%)$, stage IIIb

\footnotetext{
${ }^{1}$ Đại học Y Hà Nội

${ }^{2}$ TT Y học hạt nhân và ung bướu, Bệnh viện Bạch Mai ${ }^{3}$ Trung tâm Giải phẫu bệnh và tế bào học, Bệnh viện Bạch Mai

${ }^{4}$ Bênh viện Bach Mai

Chịu trách nhiệm chính: Bùi Tiến Công

Email: drcongbui@hmu.edu.vn

Ngày nhận bài: 10.9.2021

Ngày phản biện khoa học: 3.11 .2021

Ngày duyệt bài: 11.11.2021
}

(43.0\%) and stage IV (57.0\%) ). $43.0 \%$ of the study patients did not express PD L1, 57.0\% of the study patients had a positive PD L1 test result, from weak to strong level. EGFR mutation rate and mutation-free rate were $55.3 \%$ and $44.7 \%$, respectively. The maxSUV value at primary lung tumor in the EGFR positive group (11.2 \pm 5.7$)$ was significantly lower than that of the negative EGFR group $(15.8 \pm 6.2)$ $(p=0,04)$. Using the ROC chart, the area under the curve (AUC) of maxSUV in diagnosing positive EGFR was $0.654(p<0.05)$. Combining 4 factors including maxSUV, gender, and smoking status gives better positive EGFR diagnosis results, specifically, the area under the curve (AUC) of the 4 factors is $0.706(p)$. $<0.05$ ). Conclusion: FDG PET/CT characteristics are relevant and valuable in predicting EGFR mutation status in lung adenocarcinoma patients.

Keywords: Lung cancer, adenocarcinoma, FDG PET/CT, EGFR

\section{I. ĐẶT VẤN ĐỀ}

Ung thư phổi (UTP) là bệnh có tỷ lệ mắc và tỷ lệ tử vong cao trên thế giới, theo GLOBOCAN 2020, UTP là môt trong những bênh đứng thứ 2 về tỷ lệ mắc mới với gần 2,1 triệu ca mới được chẩn đoán ở cả hai giới, đứng đâu ở nam giới và đứng hàng thứ 3 ở nữ giới [1].

UTP có độ ác tính cao, tiến triển nhanh, tiên lượng xấu, tỷ lệ sống thêm sau 5 năm khoảng $15 \%$ ở cả 2 giới. Tuy nhiên đa số các bệnh nhân được chẩn đoán bệnh ở giai đoạn IIIb, IV. Trong những năm gân đây, thuốc kháng phân tử nhỏ tyrosine kinase như gefitinib, erlotinib, afatinib, osimetinib là phương pháp điều trị hiệu quả, kéo dài thời gian sống còn toàn bô các bênh nhân UTP giai đoạn IIIb, IV có đột biến gen ĖGR. Xét nghiệm xác định tình trạng đột biến gen EGFR được khuyến cáo tiến hành thường quy cho các bệnh nhân UTP không tế bào nhỏ giai đoạn tiến xa nhằm lựa chọn chiến lược điều tri cho bệnh nhân. Các nghiên cứu cho thấy yếu tố như giới tính, tiền sử hút thuốc lá, thể mô bệnh học có liên quan đến tình trạng đột biến gen EGFR, tuy nhiên chưa đủ để dự đoán tình trạng đột biến gen EGFR ở bệnh nhân ung thư phổi. Các phương pháp xác định tình trạng đột biến gen EGFR chủ yếu vẫn là DNA được tách từ khối bênh phẩm thông qua sinh thiết khối u hoăc tổn thương di căn và xét nghiệm mẫu bênh phẩm (dịch, máu...). Một số cơ sở có thể thực hiện xét nghiẻm sinh thiết lỏng (liquid biopsy). Những 
năm gần đây, các kỹ thuật chẩn đoán hình ảnh và y học hạt nhân đặc biệt là FDG PET/CT được áp dụng rộng rãi trong đánh giá chẩn đoán bệnh nhân ung thư phổi trước điều trị. PET/CT là kĩ thuật chẩn đoán y học hạt nhân giúp chẩn đoán sớm và cung cấp thông tin chính xác về giai đoạn bệnh, có giá trị tiên lượng ở bệnh nhân UTPKTBN. SUVmax là chỉ số quan trọng phản ánh tình trạng chuyển hoá tại vị trí tổn thương được đánh giá. Con đường tín hiệu EGFR đóng vai trò quan trọng trong sự tồn tại và tăng sinh tế bào ung thư và quá trình chuyển hoá glucose tại khối u. Do đó nghiên cứu SUVmax có thể giúp dự đoán tình trạng đột biến gen EGFR. Có nhiều nghiên cứu đã được tiến hành tuy nhiên kết quả nghiên cứu chưa có sự thống nhất. Một số nghiên cứu cho kết quả không có sự khác nhau SUVmax ở hai nhóm EGFR âm tính và dương tính $[2,3]$. Các tác giả khác lại cho kết quả nghiên cứu SUVmax thấp hơn ở nhóm EGFR âm tính [48] hoặc cao hơn ở nhóm EGFR dương tính [910]. Vì vây chúng tôi thực hiện nghiên cứu với mục tiêu "Nghiên cứu giá trị của ${ }^{18}$ FDG PET/CT dự đoán tình trạng đột biến gen EGFR ở bệnh nhân ung thư phổi biểu mô tuyến".

II. ĐỐI TƯợNG VÀ PHƯƠNG PHÁP NGHIÊN CỨU

1. Phướng pháp nghiên cứu: mô tả cắt ngang

2. Đối tượng nghiên cứu: 114 bệnh nhân ung thư biểu mô tuyển của phổi giai đoạn IIIB - IV

Tiêu chuân lựa chọn bệnh nhân. Chẩn đoán ung thư phổi biểu mô tuyến

Được chụp ${ }^{18} \mathrm{FDG} P E T / C T$, xét nghiệm đột biến gen EGFR trước điều trị

Chức năng gan thận, tủy xương bình thường

Tiêu chẩn loại trừ bệnh nhân. Bệnh phẩm xét nghiệm mô bệnh học được lấy không phải tại u nguyên phát

Bệnh nhân không xác định được khối u nguyên phát trên PET/CT

3. Thời gian nghiên cứu: từ tháng $11 / 2018$ $-07 / 2020$

4. Địa điểm nghiên cứu: Trung tâm $Y$ học hạt nhân và Ung bướu Bệnh viện Bạch Mai

5. Nội nghiên cứu: Ghi nhận đặc điểm lâm sàng của bệnh nhân: tuổi, giới tính, mô bệnh học, tiền sử hút thuốc lá, tình trạng đột biến gen EGFR.

Chụp ${ }^{18}$ FDG PET/CT: mỗi bệnh nhân được tiêm tînh mạch ${ }^{18} \mathrm{FDG}$ liều $0,15 \mathrm{mCi} / \mathrm{kg}$ sau khi nhịn đói ít nhất 4 giờ. Tiến hành ghi hình sau tiêm thuốc phóng xạ 45 phút. Bệnh nhân được ghi hình từ $1 / 3$ trên đùi đến đỉnh đầu. thiết bị sử dụng là PET/CT Scanners của Siemens. Hình ảnh được xử lý bằng phần mềm Syngo Via. Kết quả hình ảnh ${ }^{18}$ FDG PET/CT được phân tích bởi 2 bác sỹ chuyên ngành y học hạt nhân có kinh nghiệm. Phân tích đặc điểm PET/CT: kích thước u phổi nguyên phát, giai đoạn $T$ trên $P E T / C T$, giá trị SUVmax tại u phổi nguyên phát, đặc điểm hạch di căn $(\mathrm{N})$ trên $P E T / C T$, giai đoạn bệnh đánh giá trên $\mathrm{PET} / \mathrm{CT}$.

6. Số liệu được phân tích bằng phần mềm SPSS 16.0

- Các thuật toán thống kê

a. Các tham số mẫu: Trung bình, độ lệch chuẩn, giá trị min, max

b. So sánh các tỉ lệ: Sử dụng test so sánh $\chi^{2}$, các so sánh có ý nghĩa thống kê khi $\mathrm{p}<0,05$. Trong trường hợp cỡ mẫu nhỏ hơn 5 thì sử dụng test $\chi^{2}$ có hiệu chỉnh Fisher.

c. So sánh các giá trị trung bình: Sử dụng test Fisher Snedecor

d. So sánh các giá trị trước và sau điều trị: Sử dụng test Student

7. Đạo đức nghiên cứu: Nghiên cứu được cho phép của Hội đồng đạo đức Đại học Y Hà Nội, chấp thuận nghiên cứu của Trung tâm $Y$ học hạt nhân và Ủng bướu, Bệnh viện Bạch Mai.

\section{KẾT QUẢ NGHIÊN CỨU}

Bảng 1: đăc điểm chung của bn nghiên cứu (n=114)

\begin{tabular}{|c|c|c|c|}
\hline \multicolumn{2}{|c|}{ Đăc điếm } & $\mathbf{n}$ & Tỷ lệ \% \\
\hline \multicolumn{2}{|c|}{ Tuối $(\bar{x} \pm s d)$} & \multicolumn{2}{|c|}{$62,3 \pm 8,5$} \\
\hline \multirow{2}{*}{ Giới: } & Nam & 72 & 63,2 \\
\hline & Nữ & 42 & 36,8 \\
\hline \multirow{2}{*}{ Hút thuốc } & Có & 54 & 47,4 \\
\hline & Không & 60 & 52,6 \\
\hline \multirow{2}{*}{$\begin{array}{l}\text { Đột biến } \\
\text { gen EGFR }\end{array}$} & Có đột biến & 63 & 55,3 \\
\hline & Không có đột biến & 51 & 44,7 \\
\hline \multirow{3}{*}{$\begin{array}{l}\text { Vị trí đột } \\
\text { biến gen } \\
\text { EGFR }\end{array}$} & Exon 19 & 33 & 52,4 \\
\hline & Exon 21 & 25 & 39,7 \\
\hline & Vị trí khác & 5 & 7,9 \\
\hline \multirow{3}{*}{$\begin{array}{l}\text { Mức độ bộ } \\
\text { lộ PDL1 }\end{array}$} & Âm tính & 49 & 43,0 \\
\hline & $1-49 \%$ & 36 & 31,6 \\
\hline & $\geq 50 \%$ & 29 & 25,4 \\
\hline \multirow{4}{*}{$\begin{array}{l}\text { Giai đoạn } \\
\text { T trên } \\
\text { PET/CT }\end{array}$} & $\mathrm{T} 1$ & 14 & 12,3 \\
\hline & T2 & 21 & 18,4 \\
\hline & T3 & 35 & 30,7 \\
\hline & $\mathrm{T} 4$ & 44 & 38,6 \\
\hline \multirow{4}{*}{$\begin{array}{l}\text { Giai đoạn } \\
\text { N trên } \\
\text { PET/CT }\end{array}$} & NO & 15 & 13,2 \\
\hline & N1 & 17 & 14,9 \\
\hline & N2 & 52 & 45,6 \\
\hline & N3 & 30 & 26,3 \\
\hline \multirow{2}{*}{$\begin{array}{c}\text { Giai đoạn } \\
\text { M trên } \\
\text { PET/CT }\end{array}$} & $\mathrm{MO}$ & 49 & 43,0 \\
\hline & M1 & 65 & 57,0 \\
\hline Giai đoạn & III & 49 & 43,0 \\
\hline
\end{tabular}




\begin{tabular}{|c|c|c|c|}
\hline $\begin{array}{c}\text { sau chụp } \\
\text { PET/CT }\end{array}$ & IV & 65 & 57,0 \\
\hline
\end{tabular}

Nhận xét: Độ tuổi trung bình của BN nghiên cứu là $62,32 \pm 8,48$, trong đó tỷ lệ nam nhiều hơn nữ với $63,2 \%$, Các BN trong nghiên cứu thuộc giai đoạn tiến xa III, IV trong đó giai đoạn
IV chiếm ưu thế $(57,0 \%)$. Phần lớn BN nghiên cứu có kết quả xét nghiệm PD L1 dương tính mức độ yếu và mạnh $(57,0 \%)$. Tỉ lệ đột biến gen EGFR $(55,3 \%)$ cao hơn tỷ lệ không có đột biến $(44,7 \%)$.

Bảng 2: Đặc điểm BN nghiên cứu liên quan đến tình trạng đột biến gen EGFR

\begin{tabular}{|c|c|c|c|c|}
\hline \multicolumn{2}{|c|}{ Đặc điếm } & Có đột biến & Không đột biến & $\mathbf{p}$ \\
\hline Tuố & & $60,1 \pm 10,4$ & $61,2 \pm 12,3$ & 0,511 \\
\hline \multicolumn{2}{|c|}{ SUVmax } & $11,2 \pm 5,7$ & $15,8 \pm 6,2$ & 0,04 \\
\hline \multirow{2}{*}{ Giới: } & Nam & $18(25 \%)$ & $54(75 \%)$ & \multirow{2}{*}{0,01} \\
\hline & Nũ & $29(69,1 \%)$ & $13(31 \%)$ & \\
\hline \multirow{2}{*}{ Hút thuốc } & Có & $18(30 \%)$ & $42(70 \%)$ & \multirow{2}{*}{0,01} \\
\hline & Không & $29(53,7 \%)$ & $25(46,3 \%)$ & \\
\hline \multirow{3}{*}{ Mức độ bộc lộ PDL1 } & Am tính & $16(32,7 \%)$ & $33(67,4 \%)$ & \multirow{3}{*}{0,228} \\
\hline & $1-49 \%$ & $16(44,4 \%)$ & $20(55,6 \%)$ & \\
\hline & $\geq 50 \%$ & $15(51,7 \%)$ & $14(48,3 \%)$ & \\
\hline \multirow{2}{*}{$\begin{array}{c}\text { Giai đoan sau chụp } \\
\text { PET/CT }\end{array}$} & III & $13(28,3 \%)$ & $33(71,7 \%)$ & \multirow{2}{*}{0,021} \\
\hline & IV & $34(50 \%)$ & $34(50 \%)$ & \\
\hline
\end{tabular}

Nhận xét: Giới tính, giai đoạn bệnh, tiền sử hút thuốc lá có liến quan có ý nghĩa thống kê với tình trang đột biến gen EGFR $(p<0,01)$ và mức độ bộc lộ PD L1 Không có liên quan có ý nghĩa thống kê với tình trạng đột biến gen EGFR $(p=0,228)$.

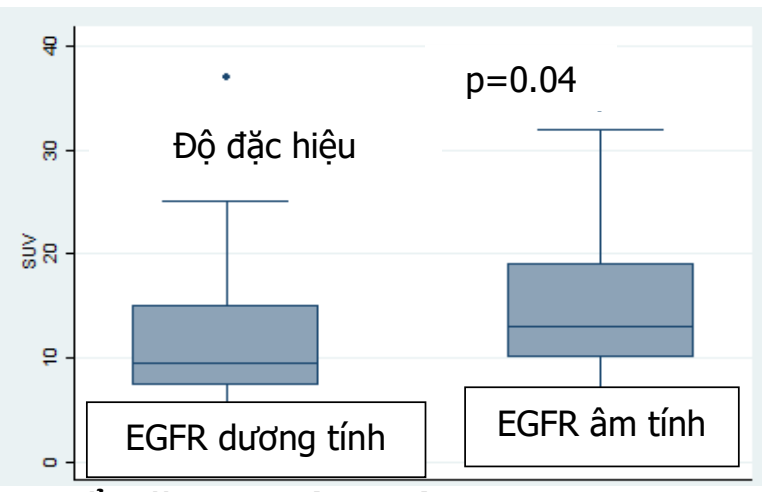

Biểu đồ 1: So sánh giá trị SUVmax tại u phổi nguyên phát theo tình trạng đột biên EGFR

Nhân xét: Giá trị SUVmax tại khối u phổi nguyên phát ở nhóm EGFR dương tính thấp hơn có ý nghĩa thống kê so với nhóm EGFR âm tính.

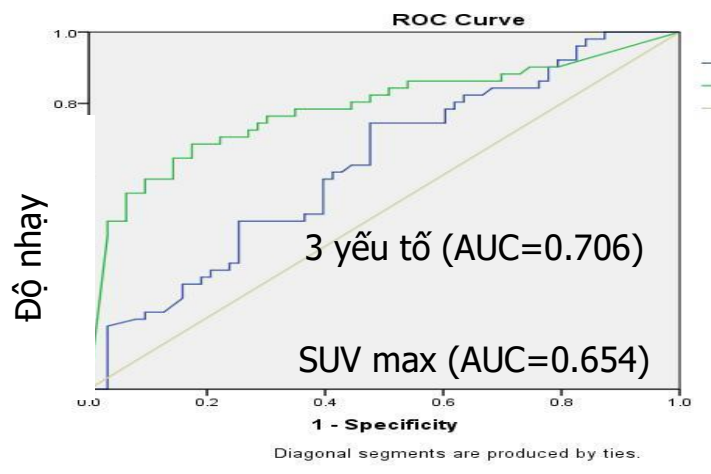

Biểu đồ 2: Giá trị dư báo tình trạng đột biến gen EGFR của SUVmax và SUVmax kêt hợp các đặc điểm giới tính, tiền sử hút thuốc, múc độ bốc lô PD L1

Nhân xét: Sử dụng biểu đồ ROC cho thấy, diện tích dưới đường cong (AUC) của SUVmax trong chẩn đoán EGFR dương tính là 0,654 $(p<0,05)$. Kết hợp 3 yếu tố SUVmax, giới, tiền sử lá hút thuốc cho kết quả chẩn đoán EGFR dương tính tốt hơn, cụ thể diện tích dưới đường cong (AUC) của 3 yếu tố là $0,706(p<0,05)$.

\section{BÀN LUÂ̂N}

Nghiên cứu 114 bệnh nhân ung thư biểu mô tuyến của phổi giai đoạn IIIB, IV từ tháng 11 năm 2018 đến tháng 8 năm 2020. Kết quả nghiên cứu cho thấy độ tuổi trung bình của BN nghiên cứu là $62,3 \pm 8,5$, trong đó độ tuổi thường gặp là từ $50-70$ tuổi. Tỉ lệ nam nhiều hơn nữ tương ứng là $63,2 \%$ và $36,8 \%$. Kết quả này cũng phù hợp với đặc điểm bệnh nhân nghiên cứu của các tác giả khác như Đinh Thị Nguyệt (2018). Các bệnh nhân nghiên cứu thuộc giai đoạn IIIb và giai đoạn IV tương ứng chiếm. $43,0 \%$ và $57,0 \%$, với đặc điểm khối u nguyên phát tương ứng T1,T2,T3,T4 lần lướt là 12,3\%, $18,4 \%, 30,7 \%$ và 38,6\%. Trong khi đó Đinh Thi Nguyệt (2018) T1 là 10,9\%, T2 là 23,6\% T3 là $17,8 \%$, T4 là 47,7\% Do nghiên cứu của chúng tôi chỉ tiến hành trên nhóm bênh nhân giai đoan IIIb, IV do đó giai đoạn T3 và T4 đánh giá trền $\mathrm{PET} / \mathrm{CT}$ chiếm ưu thế trong nghiên cứu của chúng tôi. Tỷ lệ bệnh nhân có bộc lộ PD L1 là 
$77,0 \%$ trong đó có $31,6 \%$ bênh nhân dương tính yếu (1- 49\%) và $25,4 \%$ dương tính mạnh ( $\geq$ $50 \%)$. Tỷ lệ đột biến gen EGFR dương tính $(55,26 \%)$ cũng cao hơn so với nhóm âm tính
(44,74\%) cũng tương đồng với kết quả nghiên cứu của Mai Trọng Khoa và cộng sự trong nghiên cứu PIONEER (2014) có tỉ lệ đột biến gen EGFR là $62,5 \%$ ở BN Việt Nam.

Bảng 3: Tổng hợp các nghiên cứu so sánh SUVmax ở 2 nhóm EGFR dương tính và âm tính [2-10]

\begin{tabular}{|c|c|c|c|c|}
\hline Tác giả & $\begin{array}{c}\text { Số bệnh } \\
\text { nhân }(\mathbf{n})\end{array}$ & $\begin{array}{c}\text { Tình trạng đột } \\
\text { biến EGFR }\end{array}$ & $\begin{array}{c}\text { Giai đoạn BN } \\
\text { nghiên cứu }\end{array}$ & $\begin{array}{c}\text { SUVmax cut } \\
\text { off }\end{array}$ \\
\hline Putora et al (2) & 28 & $14(50 \%)$ & I - IV & NA \\
\hline Lee et al (3) & 206 & $47(23 \%)$ & I - IV & NA \\
\hline Na et al (4) & 100 & $21(21 \%)$ & I - IV & $<9,2$ \\
\hline Guan et al (5) & 316 & $126(39,9 \%)$ & I - IV & $<8,1$ \\
\hline Cho et al (6) & 61 & $30(49,1 \%)$ & I - IV & $<9,6$ \\
\hline Takamochi et al (7) & 734 & $334(46 \%)$ & I - IV & $<2,69$ \\
\hline Lv et al (8) & 808 & $371(45,9 \%)$ & I - IV & $<7$ \\
\hline Ko et al (9) & 132 & $69(52 \%)$ & I - IV & $>6$ \\
\hline Kanmaz et al (10) & 218 & $63(28,9 \%)$ & I - IV & $>13,65$ \\
\hline
\end{tabular}

Các kết quả nghiên cứu cho thấy việc xác định tình trạng đột biến gen EGFR đóng vai trò quan trọng trong việc lựa chọn phương pháp điều trị ở bệnh nhân ung thư phổi giai đoạn tiến xa. Đặc biệt các nghiên cứu cho thấy thuốc phân tử nhỏ kháng tyrosine kinase giúp kéo dài thời gian sống bệnh không tiến triển và thời gian sống còn toàn bộ. Nghiên cứu của tác giả Putora, tác giả Lee và cộng sự cho thấy sự khác biệt có ý nghĩa thống kê mức hộ hấp thu FDG tại khối u nguyên phát giữa 2 nhóm EGFR dương tính và âm tính. Kết quả nghiên cứu của chúng tôi cho thấy giá trị SUVmax tại khối u phổi nguyên phát ở nhóm EGFR dương tính thấp hơn có ý nghĩa thống kê so với nhóm PD L1 âm tính và Sử dụng biểu đồ ROC cho thây, diện tích dưới đường cong (AUC) của SUVmax trong chẩn đoán EGFR dương tính là $0,654(p<0,05)$. Kết hợp 3 yếu tố SUVmax, giới, tiền sử lá hút thuốc cho kết quả chẩn đoán EGFR dương tính tốt hơn, cụ thể diện tích dưới đường cong (AUC) của 3 yếu tố là $0,706(p<0,05)$. Như vậy SUVmax tại khối u nguyên phát có thể được xem như là yếu tố dự đoán tình trạng đột biến gen EGFR. Kết quả này cũng tương đồng với nhiều nghiên cứu của các tác giả khác như Zhilei Lv trên nhóm bệnh nhân nghiên cứu với $n=808$ bệnh nhân, cho thấy với SUVmax nhỏ hơn 7 có giá trị dự đoán EGFR dương tính với $A U C=0,557$, khi kết hợp với các yếu tố khác như giới tính, tiền sử hút thuốc, thể mô bệnh học thì khả năng dự đoán dương tính cao hớn (AUC $=0,697)[4-8]$. Tuy nhiên một số nghiên cứu khác của tác giả Kanmaz $(n=218)$, Ko $(n=132)$, Kanmaz $(n=218)$ cho kết quá SUVmax ở nhóm bệnh nhân EGFR dương tính cao hơn so với nhóm bệnh nhân có EGFR âm tính $[9,10]$. Các kết quả nghiên cứu cho thấy
SUVmax có thể được sử dụng như mọt yếu tốt dự đoán tình trạng đột biến gen EGFR ở bệnh nhân ung thư phổi. Tư nhiên vẫn cần những nghiên cứu trên số lượng bệnh nhân lớn hơn để có kết quả thuyết phục hơn.

\section{KẾT LUÂ̂N}

Nghiên cứu 114 bệnh nhân ung thư biểu mô tuyến của phổi giai đoạn IIIb, IV được chụp ${ }^{18}$ FDG PET/CT, xét nghiệm EGFR trước điều trị từ 11/2018 đến 07/2020 tại trung tâm $Y$ học hạt nhân và Ung bướu, Bệnh viện Bạch Mai chúng tôi có một số kết luận sau:

Độ tuổi trung bình $62,3 \pm 8,4$, tỷ lệ nam $(63,2 \%)$ nữ $(36,8 \%)$, giai đoạn IIIb $(42,98 \%)$ và giai đoạn IV (57,0\%). 43,0\% bệnh nhân nghiên cứu khồng bộc lộ PD L1, 57,0\% BN nghiên cứu có kết quả xét nghiệm PD L1 dương tính mức độ yếu đến manh. Tỉ lệ đột biến gen EGFR và tỷ lệ không có đột biến tương ứng 55,3\% và 44,7\%.

Giá trị SUVmax tại khối u phổi nguyên phát ở nhóm EGFR dương tính $(11,2 \pm 5,7)$ thấp hơn có ý nghĩa thống kê so với nhóm EGFR âm tính $(15,8 \pm 6,2)(p=0,04)$. Sử dụng biểu đồ ROC cho thấy, diện tích dưới đường cong (AUC) của SUVmax trong chẩn đoán EGFR dương tính là $0,654(p<0,05)$. Kết hợp 3 yếu tố SUVmax, giới, tiền sử hút thuốc lá cho kết quả chẩn đoán EGFR dương tính tốt hơn, cụ thể diện tích dưới đường cong (AUC) của 3 yếu tố là $0,706(p<0,05)$.

\section{TÀI LIỆU THAM KHẢO}

1. World Health Organization. Globocan (2018): Estimated cancer incidence, mortality and prevalence worldwide in 2018, < globocan.iarc.fr/ pages/online.aspx>, xem 9/11/2018.

2. Putora PM, Fruh M, Muller J. FDG-PET SUVmax values do not correlate with epidermal growth factor receptor mutation status in lung 
adenocarcinoma. Respirology. $\quad 2013 ; 18(4)$ :734735. doi:10.1111/resp.12083

3. Lee SM, Bae SK, Jung SJ, Kim CK. FDG uptake in non-small cell lung cancer is not an independent predictor of EGFR or KRAS mutation status: a retrospective analysis of 206 patients. Clin Nucl Med. 2015;40(12):950-958.

4. Na II, Byun BH, Kim KM, et al. 18F-FDG uptake and EGFR mutations in patients with non-small cell lung cancer: a single-institution retrospective analysis. Lung Cancer. 2010;67(1):76-80.

5. Guan J, Xiao NJ, Chen M, et al. 18F-FDG uptake for prediction EGFR mutation status in non-small cell lung cancer. Medicine. 2016;95(30):e4421.

6. Cho A, Hur J, Moon YW, et al. Correlation between EGFR gene mutation, cytologic tumor markers, 18F-FDG uptake in non-small cell lung cancer. BMC Cancer. 2016;16:224.

7. Takamochi K, Mogushi K, Kawaji $H_{\text {, et }}$ al. Correlation of EGFR or KRAS mutation status with 18F-FDG uptake on PET-CT scan in lung adenocarcinoma. PLoS One. 2017;12(4):e0175622.

8. Lv Z, Fan J, Xu J, et al. Value of (18)F-FDG PET/CT for predicting EGFR mutations and positive ALK expression in patients with non-small cell lung cancer: a retrospective analysis of 849 Chinese patients. Eur J Nucl Med Mol I. 2018;45(5):735750. doi:10.1007/s00259-017-3885

9. Ko KH, Hsu HH, Huang TW, et al. Value of (1)(8)F-FDG uptake on PET/CT and CEA level to predict epidermal growth factor receptor mutations in pulmonary adenocarcinoma. Eur J Nucl Med Mol I. 2014;41(10):1889-1897. doi:10.1007/s00259014-2802

10. Kanmaz ZD, Aras G, Tuncay E, et al. Contribution of (1)(8) Fluorodeoxyglucose positron emission tomography uptake and TTF-1 expression in the evaluation of the EGFR mutation in patients with lung adenocarcinoma. Cancer Biomark. 2016;16(3):489-498. doi:10.3233/CBM-160588

\section{TÌM HIỂU TỶ LÊ, LOAI ĐộT BIẾN GEN EGFR VÀ TỶ LÊ BộC Lộ DẤU ẤN P53, KI67 Ở NGƯỜI BÊ̂NH UNG THƯ BIỂU MÔ VẢY MŨI XOANG}

\section{TÓM TẮT}

Tìm hiểu tỷ lệ, loại đột biến gen EGFR và tỷ lệ bộc lộ dấu ấn P53, Ki67 ở người bệnh ung thư biểu mũ̃ xoang nhằm mục tiêu: Xác định tỷ lệ, loại đột biến gen EGFR và sự bộc lộ các dấu ấn P53 và Ki67 ở người bệnh ung thư biểu mô vảy mũi xoang. Đối tượng nghiên cứu gồm 48 trường hợp ung thư biểu mổ vảy mũi xoang có chẩn đoán mô bênh hoc, có kết quả xét nghiệm đột biến gen EGFR trên máy Colbas 4800 và kết quả nhuôm hóa mô miễn dịch dấu ấn P53 và Ki67 trên máy nhuộm tự động Venatana (tất cả đều có chứng âm và dương, nhân định kết quả theo tiêu chuẩn của nhà sản xuất). Kết quả:Tỷ lệ đột biến chung toàn bô 4 exon là $56,3 \%$. Đôt biến điểm L861Q (exon 21$)$ chiếm nhiêu nhất $(25,1 \%)$ và đột biến exon 20 (T79M) chiếm ít nhất $(8,3 \%)$. Có $95 \%$ các trường hợp nghiên cứu bộc lộ dấu ấn P53, trong đó mức độ bộc lộ vừa và manh $(++$ và +++$)$ nhiều nhất và bằng nhau (39,6\%). 100\% các trường hợp bộc lộ dấu ấn Ki67, trong đó bộc lộ mức độ vữa $(++)$ chiếm nhiều nhất $(58,4 \%)$, mức độ bộ lộ yếu chỉ có $10,4 \%$. Ung thư biểu mô vảy không sừng hóa có tỷ lệ đột biến gen EGFR cao hơn nhóm sừng hóa nhưng tỷ lệ bộc lộ các dấu ấn P53 và ki67 không liên quan đến typ ung thư sừng hóa hay không sừng hóa. Các kết quả nghiên cứu đã được so sánh và bàn luận.

\footnotetext{
*Bệnh viện Đa khoa Tỉnh Phú Thọ

**Đai hoc Y Hà Nôi

Chịu trách nhiệm chính: Nguyễn Thế Đạt

Email: nguyenthedattmh@gmail.com

Ngày nhận bài: 14.9.2021

Ngày phản biện khoa học: 3.11.2021

Ngày duyệt bài: 16.11.2021
}

Tư khóa: Ung thư biểu mô vảy mũi xoang, đột biến EGFR, dấu ấn P53 , Ki67.

\section{SUMMARY \\ STUDYING THE RATE AND TYPE OF EGFR GENE MUTATIONS AND THE EXPRESSION RATE OF \\ P53 AND KI67 MARKERS IN PATIENTS WITH SQUAMOUS CELL CARCINOMA}

Studying the rate and type of EGFR gene mutations and the expression rate of P53 and Ki67 markers in patients with squamous cell carcinoma. Objectives: Determine the rate and type of EGFR mutations and the expression of P53 markers and Ki67 in patients with squamous cell carcinoma of the sinonasal.The study subjects included 48 cases of squamous cell carcinoma with histopathological diagnosis, EGFR mutation test results on Colbas 4800 and immunohistochemical staining results of P53 and Ki67 markers on the machineVenatana automatic dyeing. Results: The overall mutation rate of all 4 exons was $56.3 \%$. Point mutation L861Q (exon 21) accounted for the most $(25.1 \%)$ and mutation exon 20 (T79M) accounted for the least (8.3\%). There are $95 \%$ of research cases that reveal the P53 marker, in which the moderate and strong expression levels (++ and +++ ) are the most and equal (39.6\%). $100 \%$ of the cases revealed Ki67 imprint, in which moderate expression (++) accounted for the most (58.4\%), weak expression level was only $10.4 \%$. Nonkeratinizing squamous cell carcinoma has a higher rate of EGFR mutation than the keratinized group, but the rate of expression of markers P53 and ki67 is not related to the type of keratinized or non-keratinized cancer. The study results were compared and discussed.

Keywords; Nasal squamous cell carcinoma, EGFR mutation, P53 marker, Ki67marker. 